\title{
Seasonal changes in the soil moisture distribution around bare rock outcrops within a karst rocky desertification area (Fuyuan County, Yunnan Province, China)
}

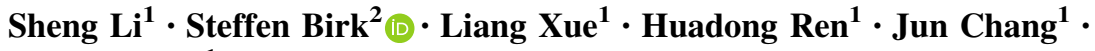 \\ Xiaohua Yao ${ }^{1}$
}

Received: 6 April 2016/ Accepted: 25 November 2016/Published online: 3 December 2016

(C) The Author(s) 2016. This article is published with open access at Springerlink.com

\begin{abstract}
The spatial and temporal soil moisture distribution is an important control on surface ecological processes in areas with rock outcrops resulting from karst rocky desertification (KRD). To explore the local effects of bare rocks within different seasons, soil moisture was measured in a KRD region (Fuyuan County, Yunnan Province, southwest China) at different depths and in different directions and distances from rock outcrops in both the dry and the wet seasons. The soil moisture north and east of the rocks was higher compared to the other directions and to the control plot. This effect is attributed to the shading by the rocks. The shading effect is evident in all seasons but more pronounced in the dry season. In the wet season, the directional dependency is restricted to the surface layer and the increase in soil moisture with depth is more pronounced around the rocks than at the control plot. This is attributed to precipitation-induced runoff from the rock outcrops infiltrating into the deeper layers at the rock-soil interface. These findings suggest the redistribution of water in the wet season and the spatial variation of evapotranspiration in the dry season are factors controlling the local soil moisture pattern around the rock outcrops.
\end{abstract}

Keywords Karst rocky desertification (KRD) - Bare bedrocks $\cdot$ Soil moisture $\cdot$ Dry and wet season

Steffen Birk

steffen.birk@uni-graz.at

1 Research Institute of Subtropical Forestry, Chinese Academy of Forestry, Fuyang 311400, Zhejiang, China

2 Institute of Earth Sciences, NAWI Graz Geocenter, University of Graz, Heinrichstr. 26, 8010 Graz, Austria

\section{Introduction}

The moisture of the surface soil layer plays a significant role in the microenvironment and is a key parameter in soil surface modeling (Peters-Lidard et al. 2001; Song et al. 2009). Soil moisture and its spatial variation are closely related to vegetation (Ferreira et al. 2007; Vivoni et al. 2008). Sufficient soil moisture is an essential condition for normal plants growth, affecting both survival and quality (Breshears et al. 1997; Peng et al. 2013; Yang et al. 2015). Therefore, the variability and pattern of soil surface moisture has received increasing attention from local to continental scales (Qiu et al. 2001; Koster et al. 2004; Feng et al. 2004; Parent et al. 2006).

The assessment and interpretation of observed soil moisture patterns is complicated by the spatial scaling of soil moisture. Western and Blöschl (1999) propose three different measures of scale, namely the "spacing," referring to the distance between the sampling locations; the "extent," referring to the size of the investigated domain; and the "support," referring to measurement volume or area. The apparent variance in soil moisture data was found to be unaffected from spacing, but to decrease with decreasing extent and increasing support (Western and Blöschl 1999; Rodriguez-Iturbe et al. 1995; Famiglietti et al. 2008).

To further complicate matters, Rodriguez-Iturbe et al. (1995) found that a power law describing the decrease in the soil moisture variance with the support area showed an increasing slope when the soil dried. This suggests that the spatial scaling of soil moisture is dependent on the wetness of the soil. Famiglietti et al. (2008) provide an overview of studies addressing the influence of the mean moisture content on the spatial variability and report field observations across scales suggesting that the standard deviation of 
soil moisture is highest at intermediate wetness and decreases toward the minimum (i.e., residual) and maximum (i.e., saturated) moisture content. Using a small experimental catchment, Western et al. (1999) observed that spatial patterns of soil moisture at the hillslope scale exhibit a high degree of organization during wet periods, but only little organization during dry periods. The spatial organization during wet periods was mainly attributed to the lateral redistribution of water, controlled by the topography of the catchment. The spatial variation of evapotranspiration was identified as another controlling factor, particularly during dry periods when evapotranspiration is an important component in the water balance.

Surface soil moisture is of particular interest in karst areas with their complex hydrogeological structure and fragile ecological environment. So far, however, little attention has been paid to the spatial and temporal variability of surface soil moisture within these fragile ecosystems specifically in the context of vegetation restoration efforts in the karst region of subtropical China (Zhang et al. 2011).

Southwest China is a typical karst ecological fragile zone (Sweeting 1993). It comprises $120,000 \mathrm{~km}^{2}$ affected by karst rocky desertification (KRD) (Wang et al. 2004). KRD results from intensive land use deteriorating the vegetation (Zhang et al. 2016). As a result of the violent human impact on the vulnerable eco-geo-environment, the soil is seriously or even thoroughly eroded, leading to a widespread exposure of bedrock, such that the carrying capacity of land declines seriously, and at last, the landscape appears similar to a desert (Huang and Cai 2007). The processes involved in KRD also affect rivers like the Yangtze and Pearl (Wang et al. 2004).

In karst settings, the removal of soil and the exposure of bare bedrock at the land surface facilitate the rapid infiltration into highly conductive cracks and solution conduits. As a consequence, the water movement is very different compared to non-karst regions. In particular, the rapid infiltration of rainfall and the low water capacity of the soil (Peng et al. 2013) make it difficult to meet the water requirement of the vegetation. Therefore, soil moisture drought occurs very frequently in KRD areas (Song et al. 2009).

KRD also results in high environmental heterogeneity and significant differences in the soil ecological conditions. In general, the microenvironment in the KRD regions changes toward drier and warmer conditions ( $\mathrm{Li}$ et al. 2009). All these factors seriously affect plant growth, leading to low plant survival rates and reduction in the efficiency of current vegetation restoration practices. The exposure of bedrock at the land surface of the KRD areas leads to a redistribution of water and soil and hence a highly heterogeneous distribution of environmental factors.
The surface bare bedrocks (Li et al. 2014), rock fragments on and in the soil (Cousin et al. 2003; Itzhak et al. 2008; Zavala et al. 2010), and the land-use types (Zucco et al. 2014) all affect the surface soil moisture.

The precipitation in southwest China shows a seasonal variation. As a result, the soil moisture also exhibits wet and dry seasons, with the dry season being longer than the wet season. The surface soil moisture distribution in a depression area of the KRD region of southwest China was found to exhibit spatial heterogeneity and anisotropy in both the dry and rainy seasons (Zhang et al. 2006). However, the spatial variability of the soil moisture in the dry season was found to be higher than that in the wet season (Zhang et al. 2011). Zhang et al. (2011) further divided the investigated field plot into two parts differing in the number of bare rocks and found that the mean soil moisture was lower where more of the bare rocks were present. The difference was statistically significant only in the dry season, which suggests that the rock outcrops might be an important factor particularly under drought conditions.

Similar to other hydrological studies addressing soil moisture distributions at the hillslope scale, Zhang et al. (2011) measured the soil moisture content within a field plot at intervals of $5 \mathrm{~m}$. Yet, the shallow and patchy soils typical of KRD areas (e.g., Wang et al. 2016) likely display heterogeneity at smaller scales. While adult trees in karst areas were found to derive the majority of water from the bedrock, seedlings, shrubs, herbs, and grass species rely on moisture from the shallow soils (Liu et al. 2014, Wang et al. 2016). Therefore, the small-scale heterogeneity of soil moisture potentially is an important control on the vegetation and thus on restoration efforts within KRD areas.

To investigate the effects of bare rocks on the soil moisture distribution at smaller scales, Li et al. (2014) measured the surface soil moisture content at distances from 5 to $25 \mathrm{~cm}$ from the rock outcrops during an extreme drought. In general, the lowest surface soil moisture was found closest to the rock. A potential explanation for this observation might be provided by Cousin et al. (2003), who suggested that rock fragments cause heating of the soil and therefore a decrease in soil moisture under drought conditions. However, Li et al. (2014) found that the soil moisture was higher in the northern direction and increased with increasing size of the bare rocks, which indicates that the shade created by the rock is a factor controlling the surface soil moisture distribution in the dry season. In contrast, Zhang et al. (2011) report higher soil moisture "immediately adjacent" to rock outcrops after heavy rain. Although the exact distance to the rock is not given, this might suggest that the surface runoff from the rock outcrops can increase the soil moisture adjacent to the rock during the wet season. This is confirmed by measurements 
in the KRD area of Shilin, China, where approximately half of the annual precipitation input received by the rock outcrops was found to be redistributed to the surrounding soil patches (Wang et al. 2016). Irrigation experiments in a semiarid area further indicate preferential flow of the water from the rock outcrops along the rock-soil interface (Sohrt et al. 2014). This redistribution of water is also reflected by an increased nitrogen supply close to rock outcrops, which creates spatial heterogeneity in the nitrogen distribution and thus might contribute to the species diversity within such environments (Göransson et al. 2014).

The purpose of this work is to explore the significance of the above-mentioned potential effects of bare rocks on the soil moisture distribution within the different seasons. To this end, the investigation by $\mathrm{Li}$ et al. (2014), who only considered extreme drought conditions, is extended to wetter time periods. Thus, the variability of the soil moisture at various depths, at various distances, and in various directions from the bare rocks is examined at the beginning, the middle, and the end of the rainy season and compared with the results from the dry season previously reported by $\mathrm{Li}$ et al. (2014). Hence, this work contributes toward understanding the effect of the exposed bare rocks on the surface soil water content in wet and dry seasons. The results from this study may support the ecological management and the restoration efforts in areas affected by KRD.

\section{Methods}

\section{Site description}

The field investigation was carried out in San-dao-qing Forestry Station $\left(25^{\circ} 02^{\prime} 30^{\prime \prime}-25^{\circ} 58^{\prime} 22^{\prime \prime} \mathrm{N}, \mathrm{E} 103^{\circ} 58^{\prime} 37^{\prime \prime}\right.$ $104^{\circ} 49^{\prime} 48^{\prime \prime}$ ), located in Fuyuan County, Yunnan Province (Fig. 1). Fuyuan County covers an area of $3251 \mathrm{~km}^{2}$ on the eastern Yunnan karst plateau. Approximately $2049 \mathrm{~km}^{2}$ of this county are karst landscapes at an early stage of development. Nearly $30 \%$ of the karst region, corresponding to $18 \%$ of the total arable land, is considered to be affected by KRD. The area has a northern subtropical monsoon climate with monthly average air temperatures ranging from 5.7 in January to $19.8^{\circ} \mathrm{C}$ in July and an annual average temperature of $13.8^{\circ} \mathrm{C}$. The annual sunshine duration is $1820 \mathrm{~h}$, and the frost-free season is 240 days. Annual average precipitation is $1332 \mathrm{~mm}$, mainly occurring during the rainy season from May to October. The main soil type is Haplic Alfisols (Chinese for "red limestone soil") according to the FAO soil classification system (FAO 1998). Rivers within the county are in the Pearl River basin. The population of the county is 716,400 , with a population density of 220 per $\mathrm{km}^{2}$ (Li et al. 2014).

\section{Data collection}

A plot with typical mid-level KRD features on the south slope of the experimental site $\left(25^{\circ} 44^{\prime} 51^{\prime \prime} \mathrm{N}, \mathrm{E} 104^{\circ} 11^{\prime} 45^{\prime \prime}\right)$ was selected for the investigation. Approximately $50 \%$ of the area is covered by vegetation and $60 \%$ represent outcrop cover ( $\mathrm{Li}$ et al. 2014). The soil depth varies between 10 and $30 \mathrm{~cm}$. In the study by Li et al. (2014), 102 rock outcrops were chosen along a 1000-m sampling line (Fig. 1). The selected rocks varied in length from 0.20 to $3.70 \mathrm{~m}$, in width from 0.19 to $3.50 \mathrm{~m}$, and in height from 0.13 to $2.5 \mathrm{~m}$ and had an average length, width, and height of about $1.00,0.94$, and $0.50 \mathrm{~m}$, respectively. The location of each rock was recorded using a GPS device (GeoXM3000, Trimble, California, USA, with an accuracy of $\pm 2.5 \mathrm{~m})$.

Whereas Li et al. (2014) measured soil moisture only in the upper $5 \mathrm{~cm}$ of the soil adjacent to the 102 rock outcrops, two bare rocks (A and B in Fig. 1; see also Fig. 2b) with uniform size and shape were selected for the more detailed investigation reported here. The geometric properties of the two selected rocks (rock A: length of $1.00 \mathrm{~m}$, width of $0.80 \mathrm{~m}$, height of $0.50 \mathrm{~m}$; rock $\mathrm{B}$ : length of $1.10 \mathrm{~m}$, width of $0.80 \mathrm{~m}$, height of $0.58 \mathrm{~m}$ ) approximately represent the above-mentioned average values of the complete data set considered by Li et al. (2014). Figure 2 illustrates the approach employed for the investigation conducted in the vicinity of these two rocks. The soil moisture at depths of $0-5,5-10$, and $10-15 \mathrm{~cm}$ was measured at distances of 5,15 , and $25 \mathrm{~cm}$ to the east, west, north, and south of the two rocks using a soil moisture sensor (5TE, Decagon Devices, Pullman, Washington, USA) coupled to a readout device (ProCheck, Decagon Devices, Pullman, Washington, USA) (Moody and Ebel 2012; Sperdouli and Moustakas 2012) (Fig. 2a). The detections were carried out after 3 consecutive days without rain on February 10, May 19, August 25, and November 23 in 2010. Three measurements were taken for each spot, and the mean was used as the water content for the subsequent statistical evaluation and interpretation. The control plot (CK, Fig. 2c) was waste grassland covering an area of $20 \mathrm{~m}^{2}$ on the same slope. The vegetation and soil characteristics of the control plot are similar to those around the rock outcrops. The soil moisture on the control plot was measured following the same procedure as described above. To avoid effects of daily soil moisture variations and thus ensure the comparability of the results, the measurements on each of the aforementioned dates were taken at the same time of day and completed within $2 \mathrm{~h}$.

At each side of the rock, an observation area of $50 \mathrm{~cm} \times 30 \mathrm{~cm}$ was divided into five parts (T1, T2, T3, T4, and NT; see Fig. 2a). For the first measurement in February 


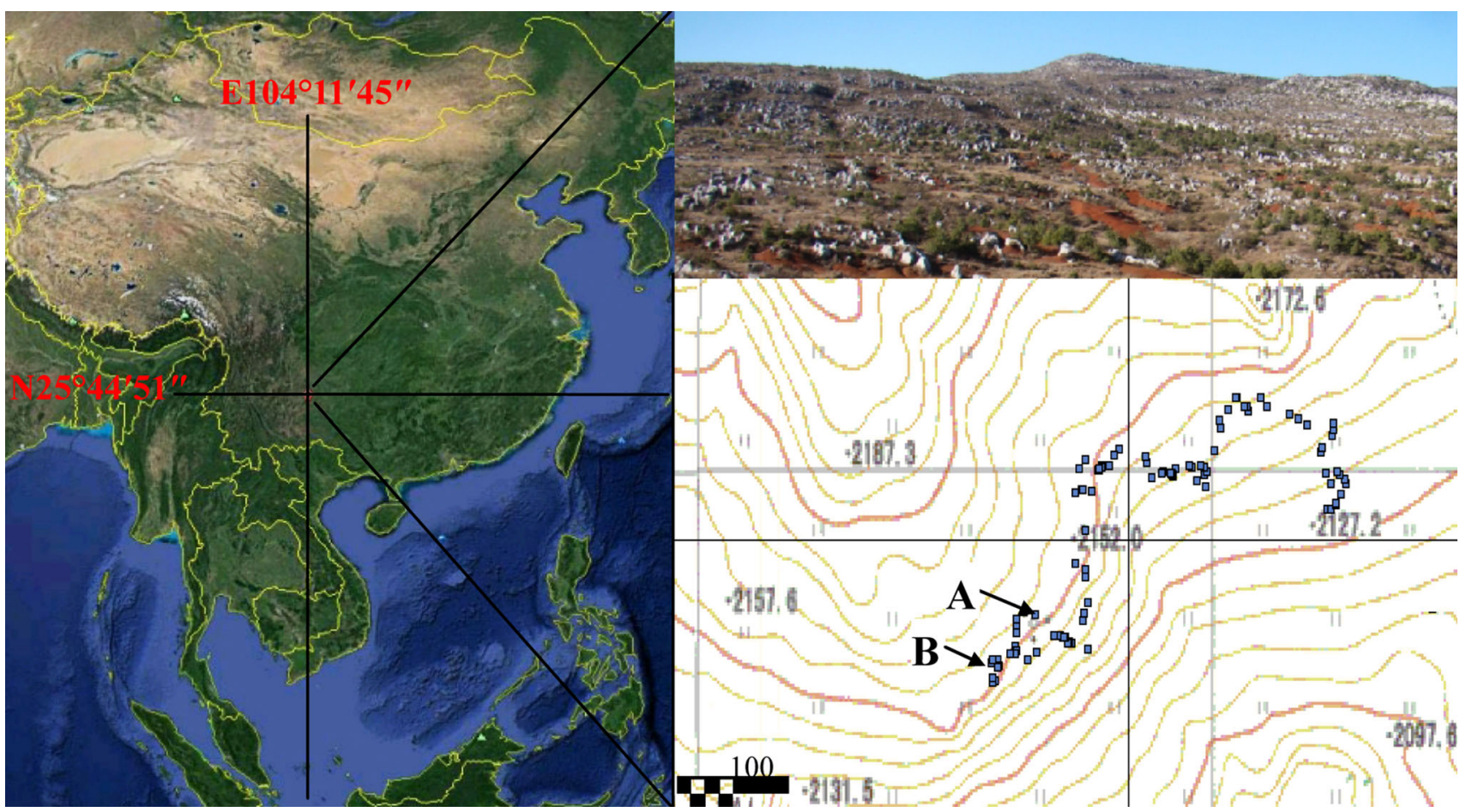

Fig. 1 Research area and map showing the location of bare rocks. (Modified after Li et al. 2014)

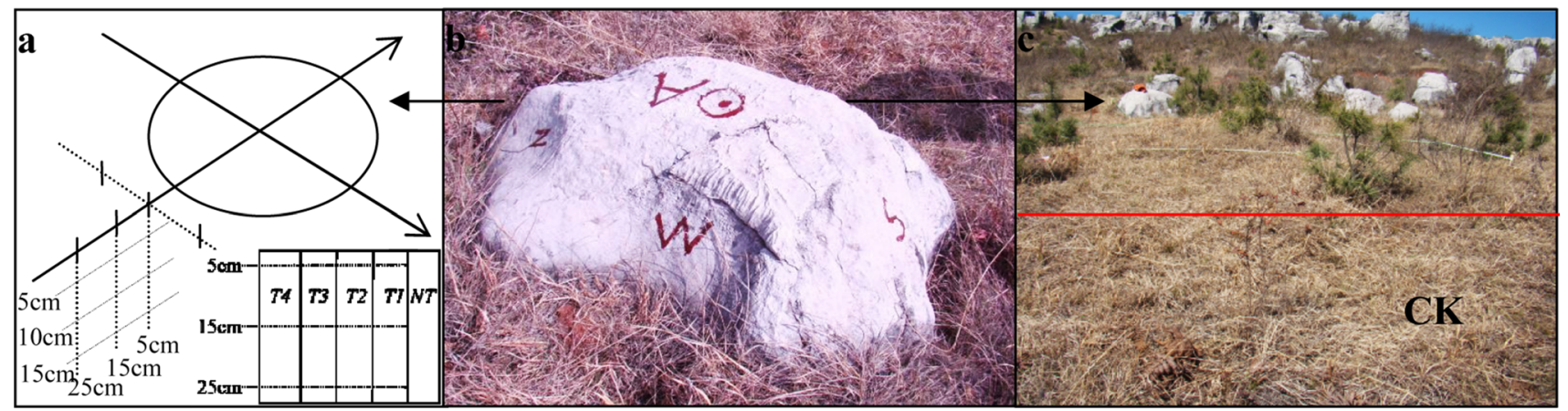

Fig. 2 Illustration of bare rock outcrops at the investigated site a schematic map of individual rock samples for soil moisture measurement at different distances and depth; b rock sample A (see Fig. 1); c control plot CK. (Modified after Li et al. 2014)

2010, a soil pit of $30 \mathrm{~cm}$ length, $10 \mathrm{~cm}$ width, and $15 \mathrm{~cm}$ depth was dug at the NT area. To avoid disturbance of the soil, the probe was inserted horizontally at different depths below ground surface $(5,10,15 \mathrm{~cm})$ and different distances from the rock $(5,15,25 \mathrm{~cm})$ within the $\mathrm{T} 1$ area. When the detection was completed, the pit in the NT area was refilled to assure the uniformity of the soil environment. The same procedure was employed for the other orientations at the two rocks and at the control plot. For the second detection in May 2010, a soil pit was dug at the T1 area, soil moisture was measured within the T2 area, and the soil pit of the T1 area was refilled after the detection was completed. The detections in August and November 2010 were carried out following the same procedure at the $\mathrm{T} 3$ and $\mathrm{T} 4$ areas.

\section{Results}

\section{Seasonal variation of surface soil moisture around the bare rocks}

Soil moisture was found to be highly significantly ( $p<0.01 ; t$ test) correlated to precipitation and exhibits an obvious seasonal variation of wet and dry (Fig. 3). Soil moisture measured in the dry season on February 10, 2010, was highly significantly $(p<0.01)$ lower than that in the rain season (August 25, 2010). The differences among soil moisture values at different distances from the rocks generally do not show clear trends and particularly were not significant in the wet season. In contrast, the soil moisture 
Fig. 3 a Average monthly rainfall of several years and of 2010 in the research area; b seasonal change in volumetric soil moisture content at the different depths and different distances from the bare bedrocks
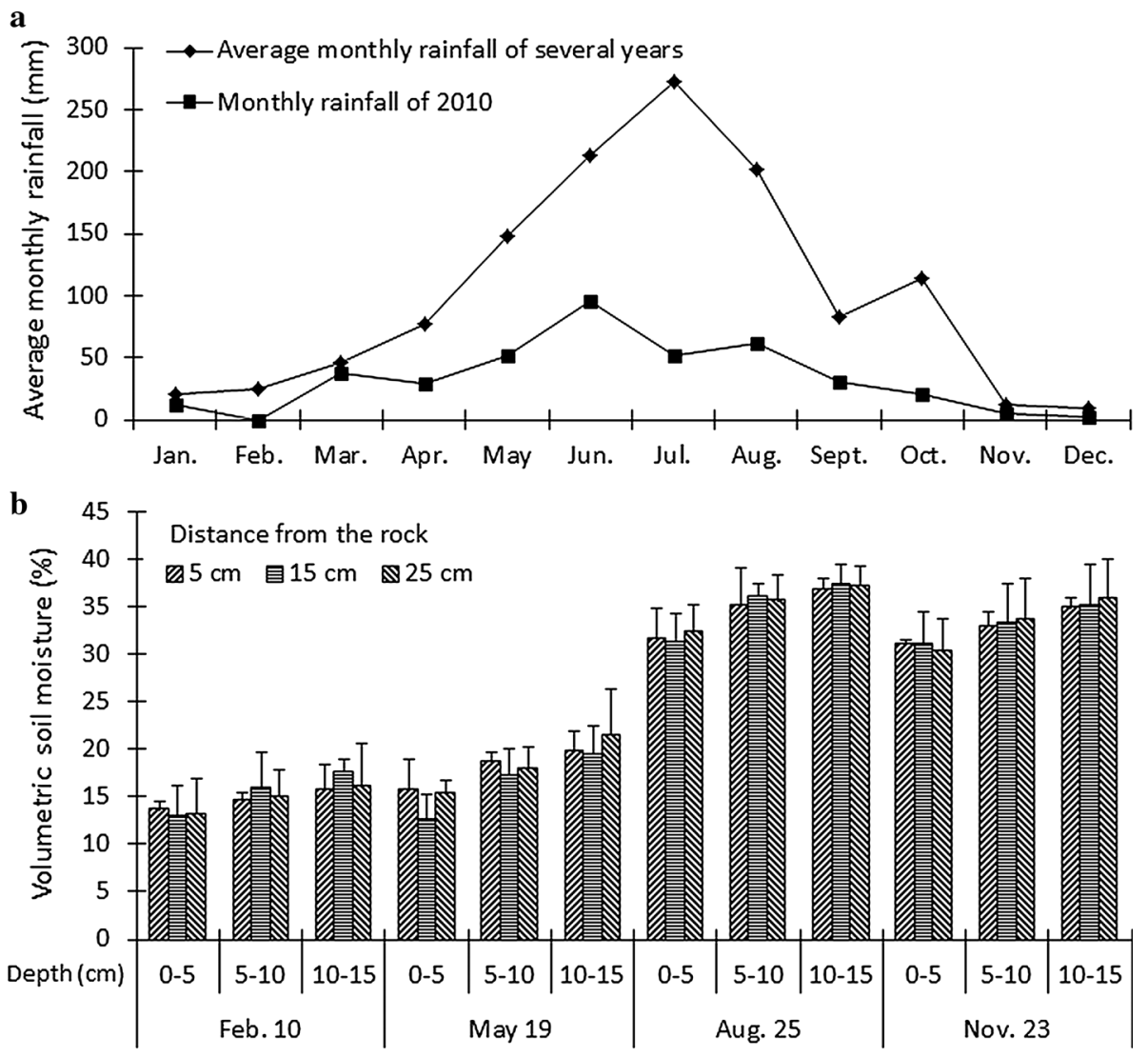

Table 1 Water contents (mean and standard deviation) at various depths in different seasons for the different directions from the bare rocks and comparison of the water contents at the control plot ("CK") and the mean obtained from the measurements in all directions from the rocks ("All")

\begin{tabular}{lllllllc}
\hline Date in 2010 & Soil layers $(\mathrm{cm})$ & E $(\%)$ & S $(\%)$ & W $(\%)$ & N $(\%)$ & All $(\%)$ \\
\hline February 10 & $0-5$ & $13.9 \pm 2.0$ & $10.5 \pm 2.0$ & $13.1 \pm 3.0$ & $15.7 \pm 1.7$ & $13.3 \pm 2.8$ \\
& $5-10$ & $16.1 \pm 2.2$ & $13.4 \pm 2.4$ & $14.6 \pm 2.9$ & $16.9 \pm 2.6$ & $15.2 \pm 2.7$ & 12.6 \\
& $10-15$ & $17.4 \pm 3.1$ & $14.6 \pm 2.4$ & $15.4 \pm 2.4$ & $18.6 \pm 2.4$ & $16.5 \pm 2.9$ & 15.6 \\
May 19 & $0-5$ & $15.8 \pm 3.0$ & $11.8 \pm 1.2$ & $13.7 \pm 2.1$ & $17.2 \pm 5.3$ & $14.6 \pm 3.7$ & 13.8 \\
& $5-10$ & $19.8 \pm 3.5$ & $14.5 \pm 1.8$ & $17.2 \pm 3.5$ & $20.2 \pm 4.5$ & $17.9 \pm 4.0$ & 15.7 \\
& $10-15$ & $21.3 \pm 1.4$ & $16.1 \pm 2.1$ & $20.0 \pm 3.3$ & $23.8 \pm 4.4$ & $20.3 \pm 4.0$ & 17.0 \\
August 25 & $0-5$ & $32.5 \pm 3.1$ & $29.5 \pm 1.7$ & $31.3 \pm 1.1$ & $33.8 \pm 1.3$ & $31.8 \pm 2.4$ & 35.0 \\
& $5-10$ & $35.6 \pm 3.8$ & $34.7 \pm 2.7$ & $35.5 \pm 2.1$ & $36.5 \pm 1.9$ & $35.6 \pm 2.6$ & 36.0 \\
& $10-15$ & $37.2 \pm 2.0$ & $36.4 \pm 2.8$ & $37.0 \pm 2.5$ & $37.7 \pm 2.5$ & $37.1 \pm 2.4$ & 36.5 \\
November 23 & $0-5$ & $31.2 \pm 5.0$ & $28.4 \pm 1.9$ & $31.0 \pm 1.4$ & $32.5 \pm 2.5$ & $30.8 \pm 2.4$ & 33.8 \\
& $5-10$ & $33.9 \pm 1.5$ & $31.7 \pm 3.8$ & $32.9 \pm 3.4$ & $34.6 \pm 1.4$ & $33.3 \pm 2.6$ & 34.1 \\
& $10-15$ & $35.5 \pm 1.2$ & $34.1 \pm 2.6$ & $35.0 \pm 2.7$ & $36.4 \pm 1.2$ & $35.3 \pm 2.6$ & 35.1 \\
\hline
\end{tabular}

clearly showed an increase with depths (Table 1; Fig. 3b). In particular, the difference in the soil moisture content at the surface $(0-5 \mathrm{~cm})$ and that at greater depth was highly significant $(p<0.01)$ in all seasons and in all directions from the bare rocks. During the dry season (February 10, May 19), the mean values measured in the vicinity of the rocks are found to be generally higher than those measured at a corresponding depth at the control plot, whereas they are more similar during the wet season (Table 1). On average (bare rocks and control plot), the surface $(0-5 \mathrm{~cm})$ soil water content on August 25, 2010, was approximately $32 \%$, whereas it was only $13 \%$ on February 10, 2010. The soil water content at a depth of $5-10 \mathrm{~cm}$ in August was $36 \%$ compared to $15 \%$ in February. At a depth of 
$10-15 \mathrm{~cm}$, the soil water content was $37 \%$ in August, but only $16 \%$ in February.

\section{Variation of soil moisture around the bare rocks in the dry season}

The surface $(0-5 \mathrm{~cm}$ depth) soil water content of the 102 rocks investigated in February 2010 (Li et al. 2014) differed highly significantly $(p<0.01)$ among the four sides of the rocks. The soil moisture north of the rocks was highest and particularly different from that in the south and the west. In the following, the soil moisture distribution in the vicinity of the bare rocks A and B on February 10, 2010 , is considered in more detail and compared with that on May 19, 2010.

Both in February and in May, the soil moisture north and east of the two bare rocks was highly significantly $(p<0.01)$ higher than that in the southern direction. The soil moisture north of the rocks was also found to be highly significantly $(p<0.01)$ or significantly $(p<0.05)$ higher than that west of the rocks in February and May, respectively. Thus, the directional dependency of the soil moisture distribution in the vicinity of the two rock samples was similar on February 10 and May 19 and shows the same pattern as described by Li et al. (2014) for the surface layer of a larger sample of 102 rocks.

To facilitate the comparison of the soil moisture distribution at different times (including the wet season-see "Variation of soil moisture around the bare rocks in the wet season" section), Fig. 4 shows differences between the soil moisture measured at rock A or B and that measured at the control plot at the corresponding depth and time. The above-described directional dependency is generally found to be similar at both rocks, but the soil moisture values are clearly higher close to rock A. In particular, almost all soil moisture values measured close to rock A are higher than those at the control plot. In contrast, the values measured at rock $B$ tend to be higher than those at the control plot only in the north and east, while those in the south and west are mostly lower than at the control plot. As a result, the mean values of the soil moisture measured close to rock $B$ and at the control plot are similar and lower than those close to rock A (Table 2).

\section{Variation of soil moisture around the bare rocks in the wet season}

The soil moisture measured north of the rocks is still found to be significantly $(p<0.05)$ or highly significantly $(p<0.01)$ higher than that in the south on August 25 and November 23, respectively. Soil moisture differences between other directions from the rocks, however, are statistically not significant. As in the dry season, the soil moisture close to rock $A$ on average is higher than that in the vicinity of rock B (Table 2), but the values measured at the control plot are now in between those measured at the two rocks and closer to those of rock $\mathrm{A}$.

Figure 5 illustrates that the directional dependency of the soil moisture is less pronounced in the wet season than in the dry season (cf. Fig. 4). Yet, the depth dependency appears to be even more obvious both at rock $\mathrm{A}$ and rock B. In fact, a closer look at the soil moisture of the individual soil layers in the wet season reveals that significant directional dependencies are only found in the surface layer $(0-5 \mathrm{~cm})$ but not below. At rock A, the surface soil moisture in the northern and eastern direction is similar to that of the control plot, but in the other directions from rock $A$ and in all directions from rock B, the surface soil moisture is lower than at the control plot. At greater depths, the soil moisture generally is higher and more similar to that of the control plot.

\section{Discussion}

The soil moisture at the field site exhibits a distinct seasonality with volumetric water contents generally below $20 \%$ in the dry season and above $30 \%$ in the wet season (Fig. 3). A similar seasonality is reported in more detail by Ries et al. (2015) for a semiarid karst area in the Jordan Rift Valley. Throughout the dry season, their records show low soil moisture values similar to those observed here. At the beginning of the wet season, the soil profiles were found to be wetted from the top to the bottom; yet after heavy rainfall events within the wet season, saturated conditions started to develop at the rock-soil interface, suggesting rapid infiltration into deeper portions of the soil. According to Ries et al. (2015), the saturated conditions persisted at maximum two days. As our measurements were taken after three days without rain, the observed water contents in the wet season are expected to represent values close to field capacity rather than saturation. Nevertheless, rapid infiltration causing temporarily high water contents at the rock-soil interface likely affect the subsequently observed soil moisture pattern, in particular the depth distribution as discussed further below.

In the dry season, the mean soil moisture in the vicinity of the bare rocks is found to be higher than that at a control plot without bare rock outcrop (Table 2). Figure 5 illustrates that this overall positive effect on the soil moisture results from the increased water content north and east of the rocks. The higher water contents on these sides of the rock indicate that the shade created by the rock reduces the evapotranspiration. Hence, as discussed by Li et al. (2014), the shading by the rock is found to be a factor controlling the soil moisture distribution in the dry season. This further 

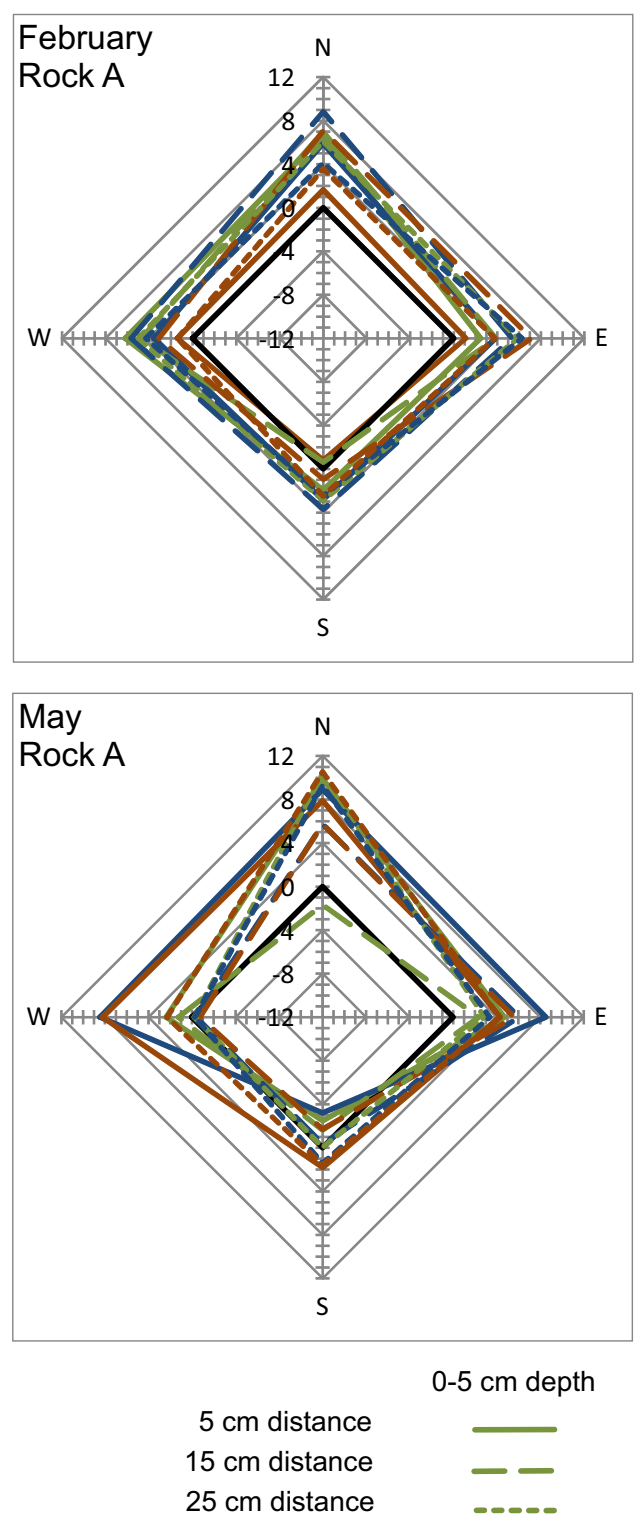

$0-5 \mathrm{~cm}$ depth

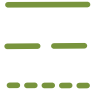

Fig. 4 Soil moisture distribution in the vicinity of rock A and rock B within the dry season (February 10 and May 19, 2010). The values represent differences between the volumetric soil moisture (in \%)

Table 2 Mean water contents and standard deviation in the vicinity of rock A and rock B and at the control plot ("CK") in different seasons

\begin{tabular}{llll}
\hline Date in 2010 & Rock A $(\%)$ & Rock B $(\%)$ & CK $(\%)$ \\
\hline February 10 & $16.8 \pm 2.6$ & $12.9 \pm 2.5$ & $12.9 \pm 2.6$ \\
May 19 & $19.0 \pm 4.5$ & $15.7 \pm 4.1$ & $15.5 \pm 1.6$ \\
August 25 & $36.5 \pm 3.3$ & $33.9 \pm 2.4$ & $35.8 \pm 0.8$ \\
November 23 & $34.6 \pm 2.5$ & $32.3 \pm 3.3$ & $34.3 \pm 0.7$ \\
\hline
\end{tabular}

suggests that the finding by Western et al. (1999), who showed that soil moisture patterns at the hillslope scale are controlled by the spatial variation of evapotranspiration particularly during dry periods, can be generally transferred
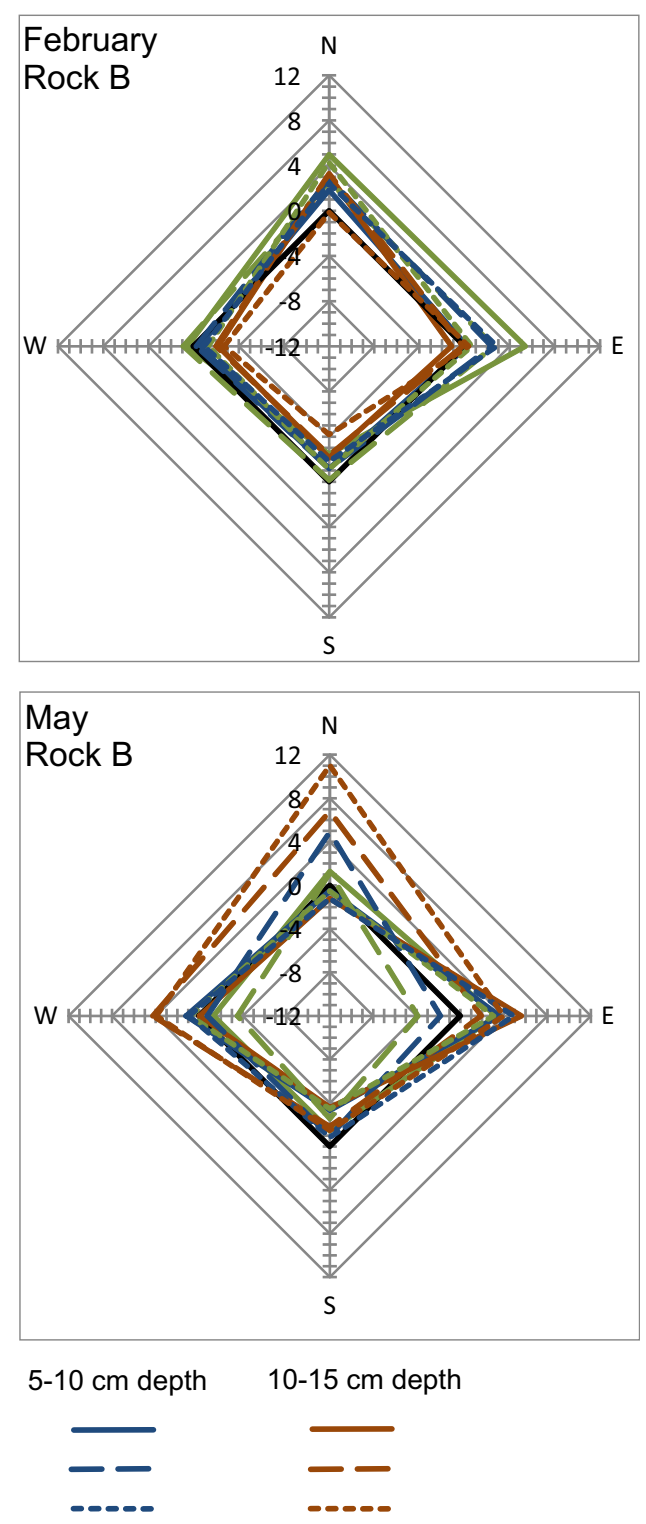

measured close to the rock and that measured at the control plot at the same depth (positive values indicating values higher than at the control plot)

to the microenvironment close to bare rock outcrops in KRD areas.

Following Western et al. (1999), the soil moisture during the wet season is expected to be mainly controlled by the redistribution of water. As mentioned in the introduction, the surface runoff from the rock outcrops is considered as a factor potentially influencing the soil moisture distribution in the vicinity of the bare rocks particularly after heavy rain events within the wet season (Zhang et al. 2011; Sohrt et al. 2014; Wang et al. 2016). Hence, the soil moisture close to the rock would be expected to be increased relative to the control plot on all sides. This is not evident from the observations in the wet season at rock $A$ and rock B (Table 2; Fig. 5). Yet the soil moisture values 

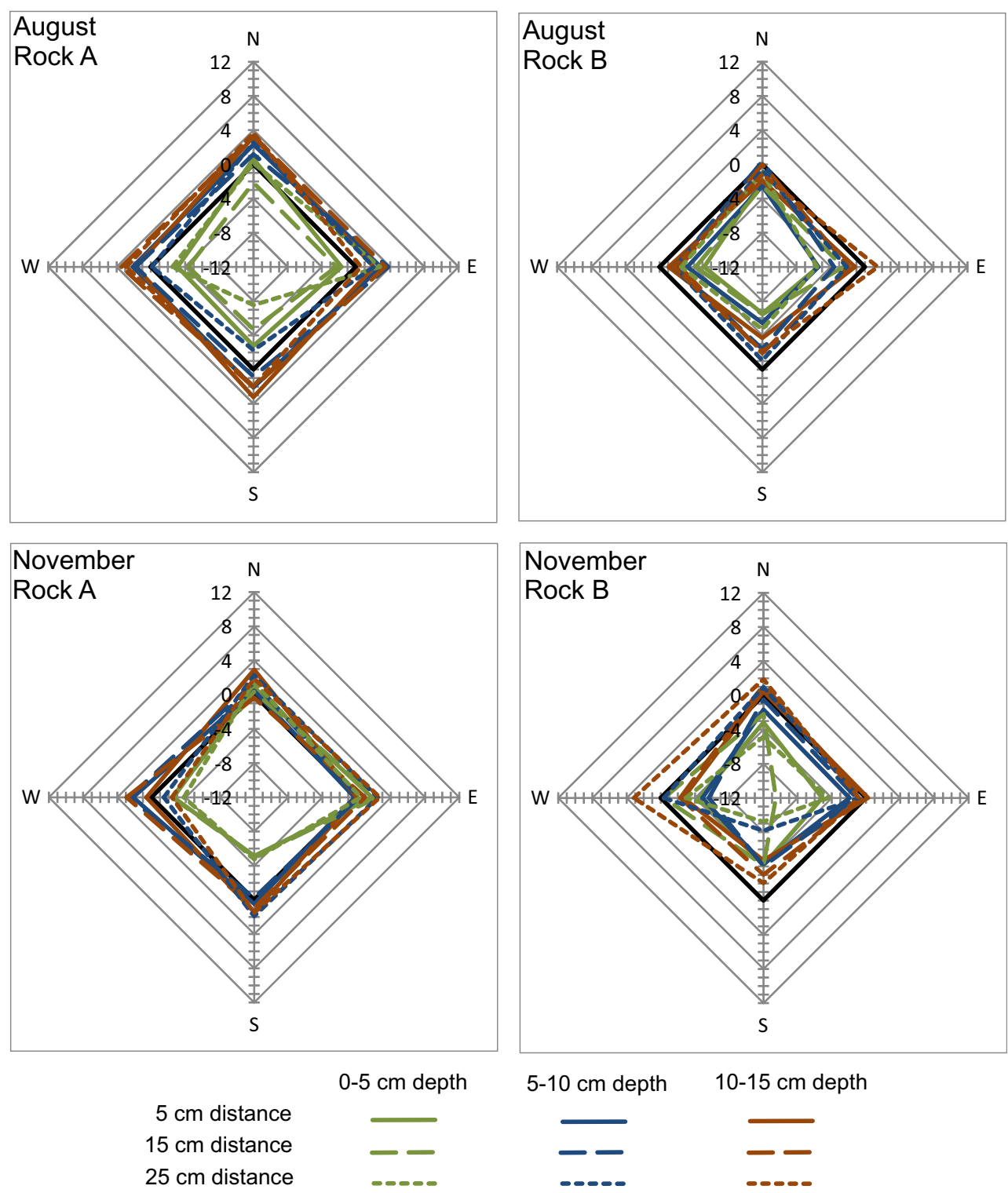

5-10 cm depth

10-15 cm depth

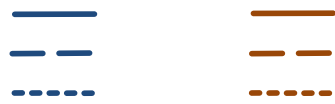

Fig. 5 Soil moisture distribution in the vicinity of rocks A and B within the wet season (August 25 and November 23, 2010). The values represent differences between the volumetric soil moisture (in

reported in Table 1 show that the differences between the soil moisture of the surface layer and that measured at greater depths are more pronounced in the vicinity of the rock outcrops than at the control plot. This might indicate a process sustaining the soil moisture at greater depth but not in the surface layer close to the rock outcrops. Sohrt et al. (2014) found that precipitation-induced runoff from rock outcrops continued below ground as preferential flow along the rock-soil interface. Hence, water infiltrating at the rock-soil interface might explain why the effect of the shading is only visible at the soil surface but not at greater depth. Thus, the redistribution of water resulting from runoff processes creates a heterogeneous spatial distribution of soil moisture (Schlesinger et al. 1990). In contrast,

$\%)$ measured close to the rock and that measured at the control plot at the same depth (positive values indicating values higher than at the control plot)

the depth distribution of the soil moisture tends to be more homogeneous when the redistribution is less effective within the dry season and at the control plot, where rock outcrops are absent.

The above-discussed patterns of the soil moisture distribution in the vicinity of the rock outcrops suggest that findings by Western et al. (1999) about the spatial organization of soil moisture pattern at the hillslope scale can at least partly be transferred to the much smaller spatial extent considered here. In particular, the patterns found in the microenvironment close to the rock outcrops are generally consistent with the understanding that evapotranspiration is a controlling process mainly in the dry season, while the redistribution of water is most effective in the wet season. 
Both the reduced evapotranspiration due to the shading of the rock and the runoff infiltrating at the rock-soil interface are expected to increase the soil moisture close to the rock outcrops. Within the dry season, the soil moisture close to the rock outcrops indeed is found to be on average higher than that at the control plot without bare rock outcrop (Table 2; Fig. 4). In the wet season, however, the soil moisture near the rock outcrops tends to be even lower than that observed at the control plot (Table 2; Fig. 5). In addition, the directional dependency of the soil moisture distribution close to the rocks is weaker in the wet than in the dry season. Whereas in the dry season differences in soil moisture contents in different directions were visible at all depths (Fig. 4), such differences were obvious in the wet season only in the surface layer (Fig. 5). The asymmetric moisture distribution in the surface layer still indicates a shading effect in the wet season. Likewise, the pronounced depth differences in the wet season suggest infiltration of runoff at the rock-soil interface. However, it seems that neither the shading nor the runoff from the rock outcrops resulted in an overall positive effect on the soil moisture in the wet season (Table 2); even in the most favorable northern direction, an increase in the soil moisture relative to the control plot is not evident (Fig. 5). This might suggest that these positive effects are compensated by some other effects. A potential explanation might be that the rock outcrops cause heating of the adjacent soil, thus enhancing evapotranspiration. A similar effect resulting from rock fragments within the soil was postulated by Cousin et al. (2003). While these authors found this effect reduces the soil moisture under drought conditions, the data presented here suggest its relevance in the wet season rather than in the dry season. A heating effect of the bare rocks could be indicated by a decrease in soil moisture with increasing distance from the rock outcrops. This, however, is not obvious from the data examined here and thus needs further investigation using more extensive data samples.

\section{Conclusion}

A sound understanding of the spatial and temporal variability of soil moisture is necessary to characterize the linkages within the soil-plant-atmosphere system. In the Chinese subtropical karst region, the spatial variability of surface soil moisture within KRD areas is still poorly understood. Thus, this work examined the seasonal changes in the small-scale soil moisture distribution within the microenvironment close to bare rock outcrops on a slope in this type of setting.

The shading of the rock outcrops was found to have a positive effect on the soil moisture north and east of the rock. The shading effect was evident in both the dry and the wet seasons, but clearly more pronounced in the dry season. In particular, the soil moisture distribution showed a directional dependency in all investigated soil layers $(0-5,5-10$, $10-15 \mathrm{~cm}$ ) in the dry season, but only in the surface layer in the wet season. The soil moisture observed in the vicinity of the rocks generally shows an increase with depth, relative to the control plot most pronounced in the wet season. Precipitation-induced runoff from the rock outcrops infiltrating along the rock-soil interface is proposed to explain this observation. This suggests that the redistribution of water is a factor controlling soil moisture patterns in the wet season, whereas the pronounced shading effect in the dry season points to evapotranspiration as a controlling factor. Similar findings previously reported at the hillslope scale thus appear to be generally transferrable to the microenvironment around the rock outcrops in KRD areas.

Yet the finding that the average soil moisture in the dry season tended to be higher in the vicinity of the bare rocks than at the control plot, while there was little difference in the wet season might indicate a mechanism operating in the wet season that reduces the soil moisture close to the rock outcrops. A heating effect of the bare rocks was proposed as such a mechanism, but it is unclear why this process would be less effective in the dry season. This therefore needs further investigation using larger data samples. The effective mechanisms and factors controlling the moisture distribution close to bare rocks thus still need to be further researched in-depth. Future research related to KRD areas in southwest China should focus on the soil moisture balance and its effective management, the mutual relationships of environmental factors, and their effects on hydrological processes and vegetation restoration strategies.

Acknowledgements Open access funding provided by University of Graz. The research was funded by the National Foundation of Natural Science Project (Nos. 31470632;30972351), and the Chinese National Key Research and Development Project (No. 2016YFC0502605). The Austrian Federal Ministry of Science, Research and Economy (BMWFW) is acknowledged for a scholarship to Li Sheng within the framework of the EURASIA PACIFIC UNINET. We are very grateful to Qian X.Q., Liu J., and Hou P. for their indispensable assistance with sample plot investigation. We also thank GuizhouPuding Desertification Ecosystem Research Station (State Forestry Administration, People's Republic of China) for support of field work. The comments by the two reviewers helped improve the paper.

Open Access This article is distributed under the terms of the Creative Commons Attribution 4.0 International License (http://crea tivecommons.org/licenses/by/4.0/), which permits unrestricted use, distribution, and reproduction in any medium, provided you give appropriate credit to the original author(s) and the source, provide a link to the Creative Commons license, and indicate if changes were made. 


\section{References}

Breshears DD, Rich PM, Barnes FJ, Campbell K (1997) Overstoryimposed heterogeneity in solar radiation and soil moisture in a semiarid woodland. Ecol Appl 7:1201-1215

Cousin I, Nicoullaud B, Coutadeur C (2003) Influence of rock fragments on the water retention and water percolation in a calcareous soil. Catena 53(2):97-114. doi:10.1016/S03418162(03)00037-7

Famiglietti JS, Ryu D, Berg AA, Rodell M, Jackson TJ (2008) Field observations of soil moisture variability across scales. Water Resour Res 44(1):W01423. doi:10.1029/2006WR005804

FAO/ISRIC/ISSS (1998) World reference base for soil resources. World soil resources reports. FAO, Rome

Feng Q, Liu YS, Mikami M (2004) Geostatistical analysis of soil moisture variability in grassland. J Arid Environ 58(3):357-372. doi:10.1016/j.jaridenv.2003.08.002

Ferreira JN, Bustamante M, Garcia-Montiel DC, Caylor KK, Davidson EA (2007) Spatial variation in vegetation structure coupled to plant available water determined by two-dimensional soil resistivity profiling in a Brazilian savanna. Oecologia 153(2):417-430. doi:10.1007/s00442-007-0747-6

Göransson H, Edwards PJ, Perreijn K, Smittenberg RH, Olde Venterink H (2014) Rocks create nitrogen hotspots and N:P heterogeneity by funnelling rain. Biogeochemistry 121(2):329-338. doi:10.1007/s10533-014-0031-x

Huang QH, Cai YL (2007) Spatial pattern of Karst rock desertification in the Middle of Guizhou Province, Southwestern China. Environ Geol 52(7):1325-1330. doi:10.1007/s00254-006-0572-y

Katra I, Lavee H, Sarah P (2008) The effect of rock fragment size and position on topsoil moisture on arid and semi-arid hillslopes. Catena 72(1):49-55. doi:10.1016/j.catena.2007.04.001

Koster RD, Dirmeyer PA, Guo ZC, Bonan G, Chan E, Cox P, Gordon CT (2004) Regions of strong coupling between soil moisture and precipitation. Science 305(5687):1138-1140. doi:10.1126/science. 1100217

Li S, Ren HD, Yao XH, Zhang SG (2009) Effects of land use type on diurnal dynamics of environment microclimate in Karst zone. Chin J Appl Ecol 20(2):387-395 (in Chinese)

Li S, Ren HD, Xue L, Chang J, Yao XH (2014) Influence of bare rocks on surrounding soil moisture in the karst rocky desertification regions under drought conditions. Catena 116:157-162. doi:10.1016/j.catena.2013.12.013

Liu Y, Huang X, Yang H, Zhong T (2014) Environmental effects of land-use/cover change caused by urbanization and policies in Southwest China Karst area-A case study of Guiyang. Habitat Int 44:339-348. doi:10.1016/j.habitatint.2014.07.009

Moody JA, Ebel BA (2012) Hyper-dry conditions provide new insights into the cause of extreme floods after wildfire. Catena 93:58-63. doi:10.1016/j.catena.2012.01.006

Parent AC, Anctil F, Parent LE (2006) Characterization of temporal variability in near-surface soil moisture at scales from $1 \mathrm{~h}$ to 2 weeks. J Hydrol 325(1-4):56-66. doi:10.1016/j.jhydrol.2005.09.027

Peng W, Song T, Zeng F, Wang K, Du H, Lu S (2013) Spatial distribution of surface soil water content under different vegetation types in northwest Guangxi, China. Environ Earth Sci 69(8):2699-2708. doi:10.1007/s12665-012-2092-2

Peters-Lidard CD, Pan F, Wood EF (2001) A re-examination of modeled and measured soil moisture spatial variability and its implications for land surface modeling. Adv Water Resour 24:1069-1083. doi:10.1016/S0309-1708(01)00035-5

Qiu Y, Fu BJ, Wang J, Chen LD (2001) Spatial variability of soil moisture content and its relation to environmental indices in a semi-arid gully catchment of the loess plateau. J Arid Environ 49(4):723-750. doi:10.1006/jare.2001.0828
Ries F, Lange J, Schmidt S, Puhlmann H, Sauter M (2015) Recharge estimation and soil moisture dynamics in a Mediterranean, semiarid Karst region. Hydrol Earth Syst Sci 19(3):1439-1456. doi:10.5194/hess-19-1439-2015

Rodriguez-Iturbe I, Vogel GK, Rigon R, Entekhabi D, Castelli F, Rinaldo A (1995) On the spatial organization of soil moisture fields. Geophys Res Lett 22(20):2757-2760. doi:10.1029/95GL02779

Schlesinger WH, Reynolds JF, Cunningham GL, Huenneke LF, Jarrell WM, Virginia RA, Whitford WG (1990) Biological feedback in global desertification. Science 247(4946):1043-1048

Sohrt J, Ries F, Sauter M, Lange J (2014) Significance of preferential flow at the rock soil interface in a semi-arid Karst environment. Catena 123:1-10. doi:10.1016/j.catena.2014.07.003

Song TQ, Peng WX, Zeng F-P, Ouyang ZW, Wu HY (2009) Spatial heterogeneity of surface soil moisture content in dry season in Mulun National Natural Reserve in Karst area. Chin J Appl Ecol 20(1):98-104 (in Chinese)

Sperdouli I, Moustakas M (2012) Spatio-temporal heterogeneity in Arabidopsis thaliana leaves under drought stress. Plant Biol 14(1):118-128. doi:10.1111/j.1438-8677.2011.00473.x

Sweeting MM (1993) Reflections on the development of karst geomorphology in Europe and a comparison with its development in China. Z Geomorphol 37:127-136

Vivoni ER, Rinehart AJ, Méndez-Barroso LA, Aragón CA, Bisht G, Cardenas MB, Engle E, Forman BA, Frisbee MD, GutiérrezJurado HA, Hong S, Mahmood TH, Tai K, Wyckoff RL (2008) Vegetation controls on soil moisture distribution in the Valles Caldera, New Mexico, during the North American monsoon. Ecohydrology 1:225-238. doi:10.1002/eco.11

Wang SJ, Liu QM, Zhang DF (2004) Karst rocky desertification in southwestern China: geomorphology, landuse, impact and rehabilitation. Land Degrad Dev 15:115-121. doi:10.1002/ldr.592

Wang DJ, Shen YX, Huang J, Li YH (2016) Rock outcrops redistribute water to nearby soil patches in Karst landscapes. Environ Sci Pollut Res 23(9):8610-8616. doi:10.1007/s11356-016-6091-9

Western AW, Blöschl G (1999) On the spatial scaling of soil moisture. J Hydrol 217(3-4):203-224. doi:10.1016/S00221694(98)00232-7

Western AW, Grayson RB, Blöschl G, Willgoose GR, McMahon TA (1999) Observed spatial organization of soil moisture and its relation to terrain indices. Water Resour Res 35(3):797-810. doi:10.1029/1998WR900065

Yang L, Chen L, Wei W (2015) Effects of vegetation restoration on the spatial distribution of soil moisture at the hillslope scale in semi-arid regions. Catena 124:138-146. doi:10.1016/j.catena.2014.09.014

Zavala LM, Jordán A, Bellinfante N, Gil J (2010) Relationships between rock fragment cover and soil hydrological response in a Mediterranean environment. Soil Sci Plant Nutr 56:95-104. doi:10.1111/j.1747-0765.2009.00429.x

Zhang W, Chen H, Wang K, Zhang J (2006) Spatial variability of surface soil water in typical depressions between hills in Karst region in dry season. Acta Pedol Sin 43(4):554-562. doi:10. $11766 / 200505250404$ (in Chinese)

Zhang J, Chen H, Su Y, Shi Y, Zhang W, Kong X (2011) Spatial variability of surface soil moisture in a depression area of Karst region. Clean Soil Air Water 39(7):619-625. doi:10.1002/clen. 201000528

Zhang JY, Dai MH, Wang LC, Zeng CF, Su WC (2016) The challenge and future of rocky desertification control in Karst areas in Southwest China. Solid Earth 7(1):83-91. doi:10.5194/ se-7-83-2016

Zucco G, Brocca L, Moramarco T, Morbidelli R (2014) Influence of land use on soil moisture spatial-temporal variability and monitoring. J Hydrol 516(6):193-199 